\title{
Inovasi Model Percepatan Pengentasan Kemiskinan Rumah Tangga Sangat Miskin \\ (Studi kasus di Kelurahan Bunulrejo, Kecamatan Blimbing, Malang)
}

\author{
The Inovation of Accelerated Poverty Alleviation Model for Very Poor \\ Households \\ (Case study in Kelurahan Bunulrejo, Blimbing District, Malang) \\ Yudiyanto tri kurniawan \\ Badan Penelitian dan Pengembangan Provinsi Jawa Timur \\ Jl. Gayung Kebonsari 56, Surabaya \\ yudi.balitbang@gmail.com
}

\begin{abstract}
Abstrak
Pemerintah Provinsi Jawa Timur telah banyak membuat kebijakan untuk menurunkan angka kemiskinan, diantaranya dengan menggulirkan Jalinkesra program bantuan hibah untuk rumah tangga sangat miskin (RTSM) yang telah dimulai sejak tahun 2010, namun dari tahun ke tahun kecepatan penurunan angka kemiskinan cenderung menurun. Untuk itu perlu adanya perancangan model percepatan pengentasan kemiskinan. Penelitian ini menggunakan metode campuran (mix methode), penggalian data dengan wawancara mendalam, survey lapangan dan dokumentasi, informan di ambil secara purposive dari data penerima manfaat. Data diolah dengan analisa SWOT. Hasil penelitian ini merekomendasikan alternatif 1 yaitu Meminimalisir kelemahan-kelemahan internal program yang sudah ada, dan alternatif 2 yaitu model percepatan pengentasan kemiskinan yang berbasis pemberdayaan perempuan.
\end{abstract}

Kata Kunci : Percepatan pengentasan kemiskinan, Rumah tangga sangat miskin, analisa SWOT

\section{Abstrac}

East Java Provincial Government has made many policies to reduce poverty, among others by rolling Jalinkesra grant aid program for very poor households (RTSM) which has been started since 2010, but from year to year the poverty reduction rate tends to decline. Therefore, it is necessary to design the acceleration model of poverty alleviation. This research uses mixed method, data mining with in-depth interview, field survey and documentation, informant is taken purposively from data of beneficiaries. Data is processed by SWOT analysis. The results of this study recommend alternative 1 that is Minimize the internal weaknesses programs that already exist, and alternative 2 is the acceleration model of poverty eradication based on women empowerment.

Keywords: Acceleration of poverty alleviation, Very poor household, SWOT analysis 


\section{PENDAHULUAN}

Pada tahun 2013 Pemerintah Provinsi Jawa Timur telah menggulirkan satu program pengentasan Kemiskinan yang bernama Jalan Lain menuju Masyarakat Sejahtera (JALINKESRA). Pada program ini Badan Pemberdayaan Masyarakat (Bappemas) sebagai leading sector berkolaborasi dengan Satuan Kerja Pemerintah Daerah (SKPD) lain yang sesuai dengan bidang usaha/kapasitas/Kapabilitas Rumah Tangga Sangat Miskin (RTSM) penerima manfaat. Bantuan yang diberikan kepada RTSM berupa Natura (tangible asset) faktor produksi atau bantuan usaha produktif, serta fasilitasi RTSM. Program ini bertujuan untuk meningkatkan motivasi berusaha (need for achievement) dari RTSM penerima bantuan, sehingga diharapkan akan meningkatkan kualitas Sumberdaya Manusia RTSM tersebut.

Implementasi program JALINKESRA dapat dikelompokkan menjadi 4 sektor, antara lain Dinas peternakan, Dinas perikanan, Dinas Koperasi dan UMKM serta Dinas Perindustrian dan Perdagangan. Pada hasil penelitian awal (Kurniawan.2015b) dinyatakan jika pada implementasi program tersebut untuk program yang dilaksanakan Dinas peternakan dan Dinas perikanan tidak efektif, sedangkan yang dilaksanakan Dinas Koperasi dan UMKM serta Dinas Perindustrian dan Perdagangan cukup baik mencapai tujuan program ini. Serta secara rerata peranan Program JALINKESRA dalam meningkatkan kualitas SDM pada RTSM di lokasi penelitian cukup baik.

Pada awal digulirkan Program ini angka kemiskinan di Provinsi Jawa Timur pada tahun 2013 sebesar 12,73\%, pada tahun 2014 turun menjadi $12,28 \%$ atau turun sebesar 0,45\%, namun pada data BPS tahun 2015 hanya turun sebesar $0,06 \%$. Dan jika kita melihat perubahan angka kemiskinan tersebut mulai tahun 2010, akan terlihat terjadi penurunan kecepatan perubahan tersebut.

Berdasarkan data-data tersebut diatas maka kami menganggap perlu untuk membuat inovasi model percepatan pengentasan kemiskinan rumah tangga sangat miskin, untuk memberikan alternatif model percepatan 
pengentasan kemiskinan bagi Pemerintah Provinsi Jawa Timur. Dengan pengambilan lokasi yang sama dengan penelitian pendahuluan, yaitu di

Kelurahan Bunulrejo, Kecamatan Blimbing, Kota Malang.

\section{PERUMUSAN MASALAH}

1. Apa saja faktor-faktor yang mempengaruhi implementasi program percepatan pengentasan kemiskinan rumah tangga sangat miskin?

2. Bagaimana model percepatan pengentasan kemiskinan rumah tangga sangat miskin?

\section{BAHAN DAN METODE}

Jenis Penelitian ini merupakan Kualitatif, dimana menurut John W.Creswell (2009:5) menyatakan bahwa Penelitian Kualitatif merupakan metode-metode untuk mengeksplorasi dan memahami makna yang dianggap berasal dari masalah sosial atau kemanusiaan, melalui proses-proses pengumpulan data yang spesifik dari para partisipan, data yang diperoleh dianalisis secara induktif dan menafsirkan makna data.

Lokasi penelitian di Kelurahan Kelurahan Bunulrejo, Kecamatan Blimbing, Kota Malang, dimana pada pertengahan tahun 2013 telah digulirkan program JALINKESRA untuk RTSM sebanyak 122 paket bantuan dari Dinas Perindustrian dan Perdagangan, Dinas Koperasi dan UMKM, Dinas Peternakan dan Dinas Perikanan dan Kelautan Provinsi Jawa Timur.

Metode Pengambilan Sample dengan kombinasi metode-metode yang dikembangkan di penelitian Kwalitatif, antara lain :

1. Metode Purposive : Berdasarkan data RTSM penerima bantuan Jalinkesra di Kelurahan Bunulrejo berdasarkan data PPLS 2008 dari Kantor Bappemas.

2. Methode Aksidental : yaitu mencari informasi sebanyak mungkin dari setiap orang yang ditemui dilokasi penelitian, baik untuk data pelengkap (suplemen) maupun data pembanding (komparasi).

Pengumpulan data dilakukan dengan teknik : Kuisioner dan

Wawancara mendalam (Deep Interview), Observasi lapangan dan 
Dokumentasi/data Sekunder dari Data statistik dari BPS, Bappemas, serta Data-data pendukung lainnya dari website/internet.

Teknik analisa data yang digunakan adalah SWOT Analisis, yang merupakan salah satu alat analisis untuk menyusun Stategi, dimana strategi ini adalah alat untuk mencapai tujuan. Hal tersebut sesuai dengan pernyataan Chandler (1962) dalam Rangkuti (1997:3) yang menyatakan bahwa "Strategi merupakan alat untuk mencapai tujuan perusahaan dalam kaitannya dengan tujuan jangka penjang, program tindak lanjut, serta prioritas alokasi sumber daya."

Sedangkan definisi yang menyebutkan unsur-unsur strategi disampaikan oleh Stiener dan Miner (1977), Mintzberg (1979) serta Argyris (1985) dalam Rangkuti (2002:4) yang menyatakan bahwa, "Strategi merupakan respon-secara terus-menerus maupun adaptif-terhadap peluang dan ancaman eksternal serta kekuatan dan kelemahan internal yang dapat mempengaruhi organisasi."

Boulton (1984) dalam Rangkuti (1997:14) menyatakan bahwa Kasus harus dijelaskan sehingga pembaca dapat mengetahui permasalahan yang sedang terjadi, selanjutnya digunakan metode yang sesuai untuk menjawab semua permasalahan secara tepat dan efektif, Caranya yaitu :

a) Memahami secara detail semua informasi

b) Melakukan analisis secara Numerik.

\section{HASIL PENELITIAN}

Dari 122 penerima bantuan di lokasi penelitian diambil 41 orang sebagai informan yang digali datanya, antara lain :

Tabel 1. Karakteristik informan berdasarkan SKPD pemberi bantuan

\begin{tabular}{|c|l|r|r|}
\hline No & \multicolumn{1}{|c|}{ SKPD } & \multicolumn{1}{|c|}{ Jumlah } & \multicolumn{1}{c|}{ Persentase } \\
\hline 1 & DISPERINDAG & 31 & 75,61 \\
\hline 2 & DISKOP & 6 & 14,63 \\
\hline 3 & DISNAK & 3 & 7,32 \\
\hline 4 & DISKANLA & 1 & 2,44 \\
\hline & Jumlah & 41 & 100,00 \\
\hline
\end{tabular}

Sumber : Data penelitian diolah. 
Berdasarkan Pedoman Umum Program Jalan Lain Menuju Kesejahteraan Rakyat (Jalin Kesra) Bantuan Rumah Tangga Sangat Miskin (RTSM) Provinsi Jawa Timur Tahun 2011 mekanisme pelaksanaan Program Jalin Kesra Bantuan RTSM dilakukan melalui beberapa tahapan seperti gambar 1 dibawah ini. Dan berdasarkan hasil penggalian data dan informasi ke 7 tahapan tersebut menjadi faktor-faktor internal dari implementasi Program Jalinkesra.

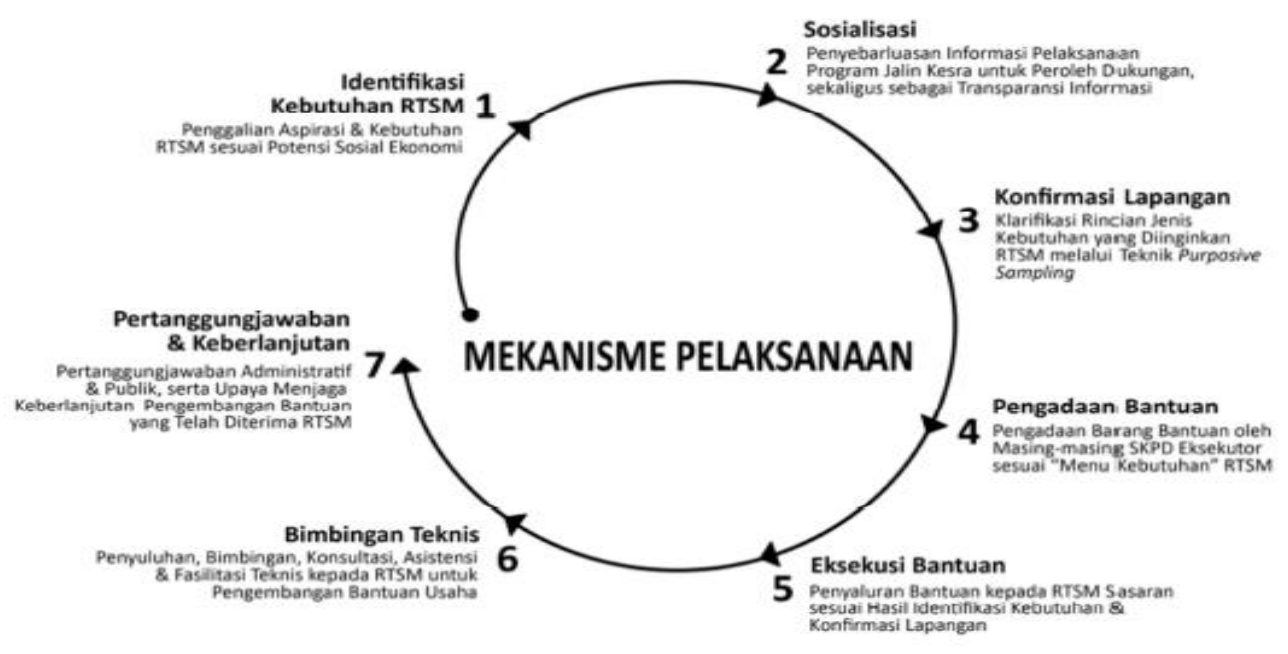

Gambar 1. Skema Mekanisme Pelaksanaan Program Jalinkesra

Sumber : Pedoman Umum Program Jalan Lain Menuju Kesejahteraan Rakyat (Jalin Kesra) Bantuan Rumah Tangga Sangat Miskin (RTSM) Provinsi Jawa Timur Tahun 2011

\section{PEMBAHASAN}

1. Faktor-faktor yang mempengaruhi implementasi program percepatan pengentasan kemiskinan rumah tangga sangat miskin

Berdasarkan hasil pengolahan data primer yang telah dikondensasikan dan data sekunder diketahui selain 7 faktor diatas ada beberapa faktor diluar proses kegiatan, yang merupakan input dari program Jalinkesra. Selanjutnya faktor-faktor internal tersebut terbagi menjadi faktor yang mendukung (Kekuatan) dan menghambat (Kelemahan). Faktor-faktor internal dapat digambarkan beserta pola hubungannya dengan tujuan program sebagai Goal-nya seperti gambar 2 dibawah ini. 


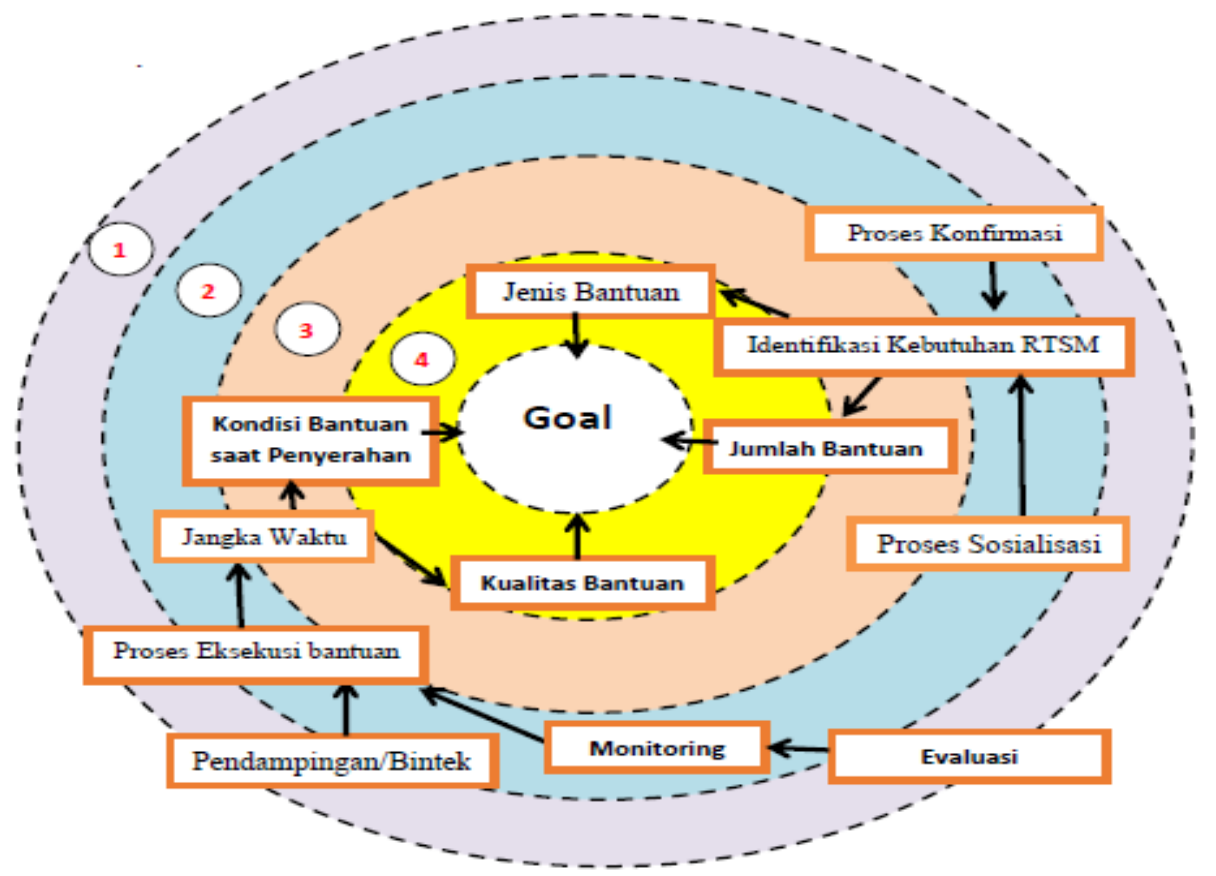

Gambar 2. Skema Faktor-faktor Internal

Sumber : Hasil Pengolahan data

Sedangkan faktor-faktor eksternal terbagi menjadi faktor yang mendukung (Potensi) dan menghambat (hambatan). Faktor-faktor eksternal tersebut dapat digambarkan unsur dan pola hubungannya seperti pada Kurniawan (2017:91).

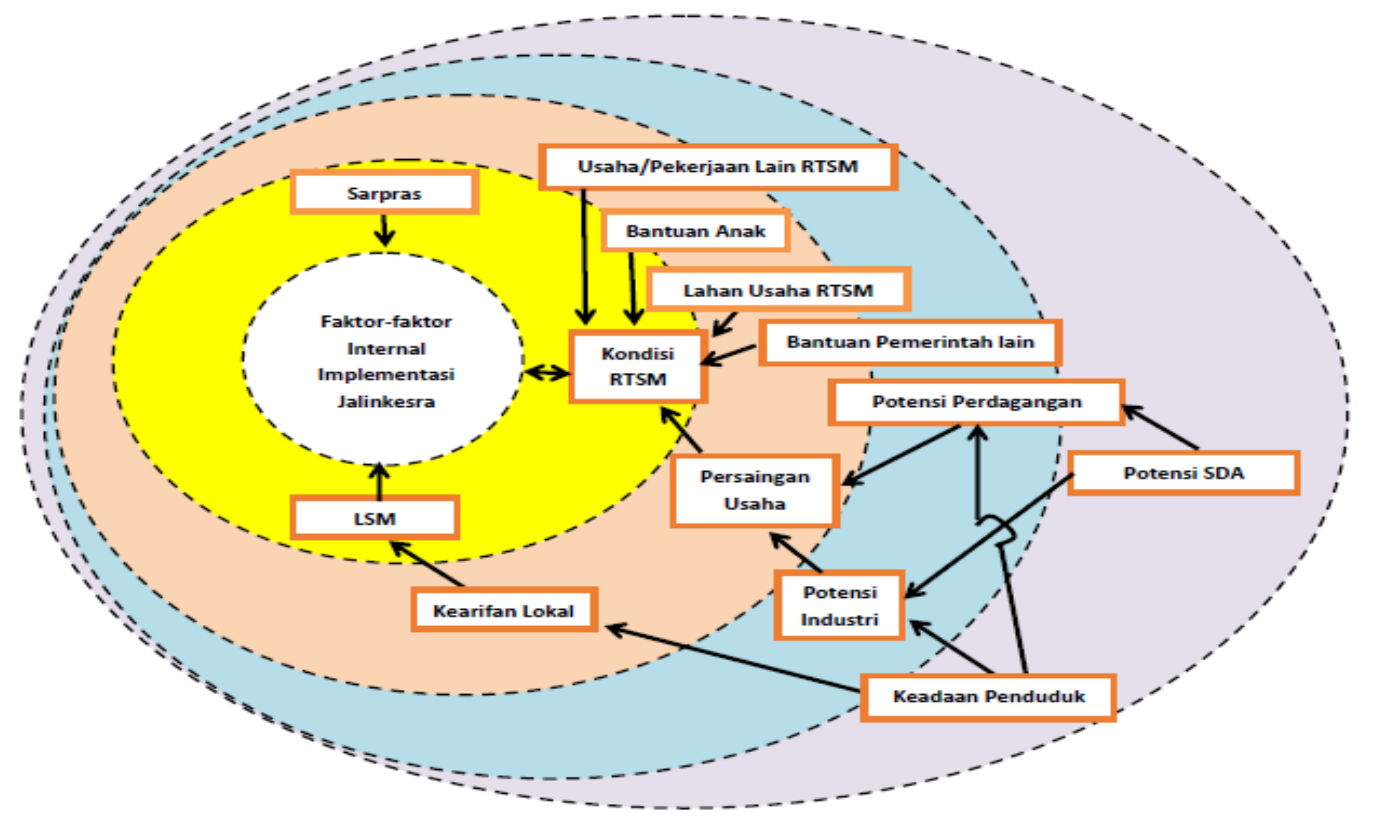

Gambar 3. Skema Faktor-faktor Eksternal

Sumber : Hasil Pengolahan data 
Kondisi Rumah Tangga Sangat Miskin (RTSM) terbagi menjadi :

1. Tingkat pendidikan RTSM

2. Ketrampilan RTSM

3. Kondisi Fisik RTSM

\section{Model percepatan pengentasan kemiskinan RTSM}

Perancangan model percepatan pengentasan RTSM kita menggunakan metode Analisa SWOT dengan menggunakan data-data hasil analisa implemetasi program Jalinkesra di wilayah Kelurahan Bunulrejo diatas dan factor-faktor eksternal dan internal diatas.

Selanjutnya kita susun matrik faktor strategi eksternal (EFAS) model percepatan pengentasan kemiskinan RTSM berdasarkan analisa hasil kondensasi data wawancara informan penerima manfaat Jalinkesra Program Bantuan RTSM di wilayah ini. Penentuan Bobot berdasarkan posisi faktor pada ring pada gambar, seperti pada kurniawan (2015a:7) dan untuk rating secara Estimasi berdasarkan data-data hasil penelitian.

Tabel 2. Matrik Faktor Strategi Eksternal (EFAS)

\begin{tabular}{|c|c|c|c|}
\hline Faktor-faktor Strategi Eksternal & Bobot & Rating & $\begin{array}{c}\text { Bobot } x \\
\text { Rating }\end{array}$ \\
\hline \multicolumn{4}{|l|}{ PELUANG } \\
\hline Kondisi Kelembagaan Masyarakat & 0,16 & 4 & 0,64 \\
\hline Kondisi sarana dan Prasarana & 0,16 & 3 & 0,48 \\
\hline $\begin{array}{l}\text { Bantuan lain Pemerintah (RASKIN, } \\
\text { BOS, dll) }\end{array}$ & 0,12 & 3 & 0,36 \\
\hline Usaha / Pekerjaan lain RTSM & 0,12 & 2 & 0,24 \\
\hline Bantuan Anak/ Keluarga & 0,12 & 2 & 0,24 \\
\hline Potensi Perdagangan & 0,08 & 4 & 0,32 \\
\hline Potensi Industri & 0,08 & 2 & 0,16 \\
\hline Keadaan Penduduk & 0,04 & 3 & 0,12 \\
\hline
\end{tabular}




\begin{tabular}{|l|c|c|c|}
\hline ANCAMAN & & & \\
\hline Ketrampilan RTSM & 0,16 & -2 & $-0,32$ \\
\hline $\begin{array}{l}\text { Kondisi Fisik RTSM (Usia, } \\
\text { Kesehatan, dll) }\end{array}$ & 0,16 & -2 & $-0,32$ \\
\hline Tingkat Pendidikan RTSM & 0,16 & -2 & $-0,32$ \\
\hline Persaingan Usaha & 0,12 & -4 & $-0,48$ \\
\hline Kepemilikan Lahan Usaha RTSM & 0,12 & -3 & $-0,36$ \\
\hline $\begin{array}{l}\text { Jumlah Anggota Keluarga } \\
\text { Tertanggung }\end{array}$ & 0,12 & -3 & $-0,36$ \\
\hline $\begin{array}{l}\text { Kearifan Lokal/ Budaya Masyarakat } \\
\text { tahlilan, dll) }\end{array}$ & 0,12 & -3 & $-0,36$ \\
\hline $\begin{array}{l}\text { Potensi Sumber Daya Alam } \\
\text { TOTAL }\end{array}$ & 0,04 & -3 & $-0,12$ \\
\hline
\end{tabular}

Sumber : Pengembangan Rangkuti (2002:22)

Selanjutnya kita susun Matrik Faktor strategi Internal (IFAS) Model Percepatan Pengentasan Kemiskinan RTSM berdasarkan Faktor-faktor Internal dalam implementasi Jalinkesra (Input dan Proses). Sedangkan Penentuan faktor-faktor mana yang masuk kategori kekuatan atau Kelemahan dan Posisi Ratingnya berdasarkan estimasi berdasarkan datadata primer dan sekunder yang diperoleh di lokasi penelitian.

Tabel 3. Matrik Faktor Strategi Internal (IFAS)

\begin{tabular}{|l|c|c|c|}
\hline \multicolumn{1}{|c|}{ Faktor-faktor Strategi Internal } & Bobot & Rating & $\begin{array}{c}\text { Bobot } x \\
\text { Rating }\end{array}$ \\
\hline KEKUATAN & 0,13 & 2 & 0,26 \\
\hline Jenis Bantuan & 0,13 & 1 & 0,13 \\
\hline Jumlah Bantuan & 0,10 & 3 & 0,29 \\
\hline $\begin{array}{l}\text { Proses Pendataan/Identifikasi } \\
\text { Kebutuhan RTSM }\end{array}$ & &
\end{tabular}




\begin{tabular}{|l|c|c|c|}
\hline Proses Eksekusi bantuan & 0,06 & 3 & 0,19 \\
\hline Proses Konfirmasi & 0,06 & 2 & 0,13 \\
\hline Proses Sosialisasi & 0,06 & 1 & 0,06 \\
\hline KELEMAHAN & 0,13 & -2 & $-0,26$ \\
\hline Kondisi Bantuan saat penyerahan & 0,13 & -2 & $-0,26$ \\
\hline Kualitas Bantuan & 0,10 & -4 & $-0,39$ \\
\hline Jangka Waktu & 0,03 & -4 & $-0,13$ \\
\hline Evaluasi & 0,03 & -3 & $-0,10$ \\
\hline Pengawasan / Monitoring & 0,03 & -3 & $-0,10$ \\
\hline Pendampingan/Bimbingan Teknis & 1.000 & & $-0,16$ \\
\hline TOTAL & &
\end{tabular}

Sumber : Pengembangan Rangkuti (2002:22)

Selanjutnya setelah diketahui nilai total masing-masing Faktor Eksternal dan Internal maka kita tentukan posisi kuadran sistem Implementasi Jalinkesra untuk RTSM di wilayah Kelurahan Bunulrejo dengan perhitungan Analisis SWOT yang dikembangkan oleh Pearce dan Robinson (1998) pada muyasarah (2010:39). Dengan melakukan pengurangan antara jumlah total faktor $\mathrm{S}$ dengan $\mathrm{W}$ dan faktor $\mathrm{O}$ dengan $\mathrm{T}$. Dari sini kita dapatkan notasi (x;y) posisi implementasi Jalinkesra di Wilayah Kelurahan Bunulrejo pada tahun 2013 sebesar $(-0,16 ; 2,20)$ terletak pada Kuadran III, sehingga dapat kita simpulkan strategi yang tepat dalam merancang Model alternatif untuk percepatan pengentasan kemiskinan RTSM. 


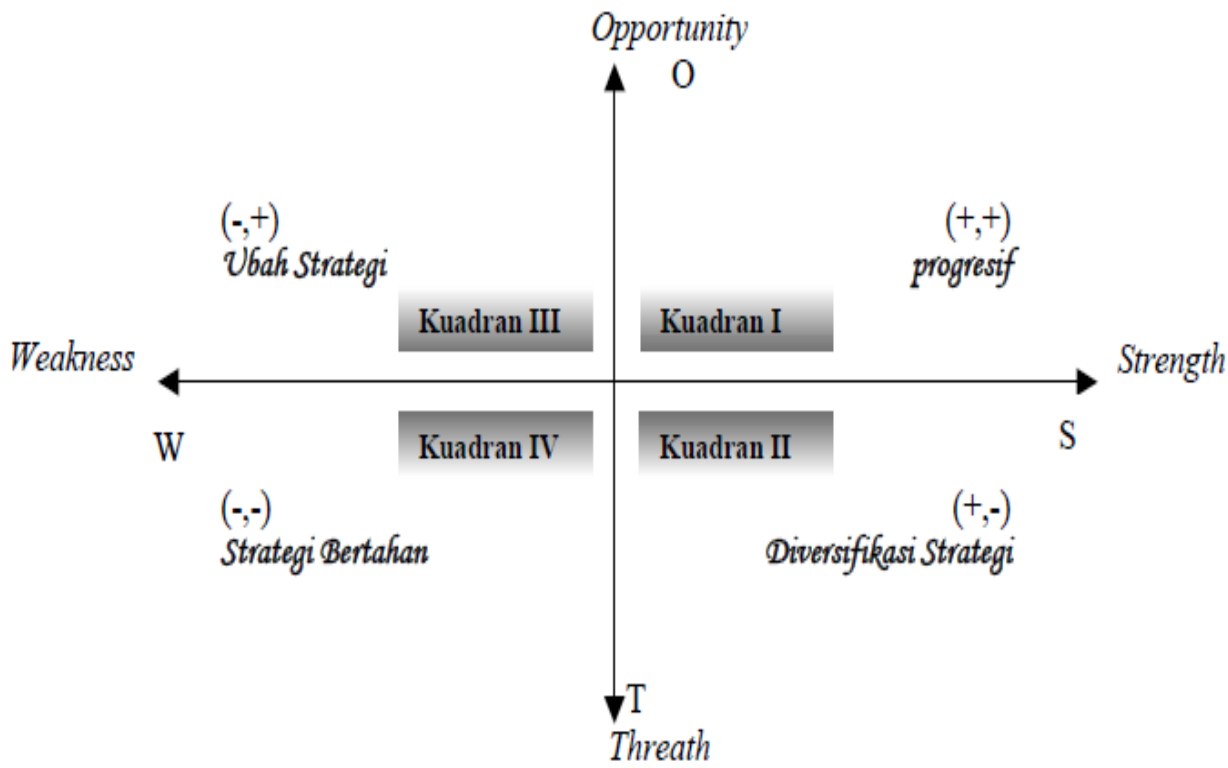

Gambar 2. Sistem Kuadran Analisa SWOT

Sumber : Muyasara (2010)

Keterangan dan penjelasan dari penjabaran SWOT Pearce dan Robinson dalam Muyasara (2010:40) untuk Kuadran III (tiga) mempunyai arti (negatif-positif) yang menandakan implementasi program Jalinkesra di Kelurahan Bunulrejo lemah namun sangat berpeluang. Rekomendasi strategi yang diberikan adalah merubah strategi atau meminimalkan masalah-masalah internal dalam implementasi program tersebut sehingga dapat mencapai hasil yang optimal.

Dan menurut kami dalam Alternatif Rancangan Model Percepatan Pengentasan Kemiskinan RTSM di wilayah ini dapat dibuat yaitu :

1. Alternatif 1, Model sama seperti Program Jalinkesra, dengan meminimalisir masalah-masalah (kelemahan-kelamahan) internal program yang sudah ada, dengan cara antara lain :

a. Jangka Waktu antara Pendataan dan Eksekusi bantuan relatif cukup lama, sehingga telah terjadi dinamika sosial-ekonomi pada RTSM, menyebabkan pencapaian tujuan program tak sesuai yang diharapkan. Untuk rentang waktu antara pendataan dan eksekusi bantuan haruslah sedekat mungkin sehingga bantuan itu dapat diterima dan dimanfaatkan tepat pada saat benar-benar dibutuhkan, misal : rentang waktu 1 bulan pada saat kondisi RTSM relatif tetap. 
b. Kualitas Bantuan perlu dilakukan pembenahan/ditingkatkan sehingga dapat benar-benar dapat dioptimalkan kemanfaatannya.

c. Kondisi Bantuan saat penyerahan, khususnya untuk bantuan berupa live natura atau ternak hidup harus benar-benar baik, supaya tidak mudah mati. Salah satunya mungkin dengan memanfaatkan produk lokal diwilayah sasaran, sehingga ternak tetap pada kondisi terbaik saat diberikan ke RTSM.

d. Pendampingan/ Bimbingan Teknis sangat perlu dilakukan untuk meningkatkan efektifitas program, terutama bantuan yang membutuhkan ketrampilan khusus dalam pemanfaatan dan pengembangannya. Pandamping program dapat diambilkan dari SDM lokal yang potensial sesuai bidang sasaran atau bentuk bantuan.

e. Pengawasan / Monitoring secara berkala dan berkelanjutan perlu terus dilaksanakan sebagai bentuk pertanggung-jawaban dan untuk menjamin keberlanjutan program ini, untuk itu dapat perlu melibatkan lembaga pemberdayaan desa setempat untuk membantu proses ini.

f. Evaluasi harus dilakukan secara berkala untuk mengetahui pencapaian tujuan yang ditetapkan, mengantisipasi permasalahan yang berpotensi muncul dan melakukan perbaikan terhadap kekurangan/kelamahan. Sebagai alternatif Bappemas dapat membuka saluran komunikasi untuk pengaduan keluhan RTSM penerima program baik secara lisan, tertulis maupun website.

2. Alternatif 2, Merancang Model baru dengan melakukan perubahan strategi, yaitu dengan kita perhatikan Pola Pemanfaatan Bantuan Jalinkesra pada RTSM di wilayah Kelurahan Bunulrejo seperti yang dapat dilihat pada tabel 3 di bawah ini. 
Tabel 4. Pola Pemanfaatan Bantuan Jalinkesra pada RTSM

\begin{tabular}{|c|c|c|c|c|}
\hline No & $\begin{array}{c}\text { Jenis Kelamin } \\
\text { Pemanfaat } \\
\text { Bantuan }\end{array}$ & $\begin{array}{c}\text { Perkembangan } \\
\text { bantuan }\end{array}$ & Jumlah & Persentase \\
\hline \multirow[t]{2}{*}{1} & \multirow[t]{2}{*}{ Perempuan } & $\begin{array}{l}\text { Berkembang/ } \\
\text { bermanfaat }\end{array}$ & 5 & 12.20 \\
\hline & & $\begin{array}{l}\text { Habis/ tak } \\
\text { dipakai }\end{array}$ & 3 & 7.32 \\
\hline \multirow[t]{2}{*}{2} & \multirow[t]{2}{*}{$\begin{array}{l}\text { Laki-laki diberikan } \\
\text { pada Perempuan }\end{array}$} & $\begin{array}{l}\text { Berkembang/ } \\
\text { bermanfaat }\end{array}$ & 8 & 19.51 \\
\hline & & $\begin{array}{l}\text { Habis/ tak } \\
\text { dipakai }\end{array}$ & 1 & 2.44 \\
\hline \multirow[t]{3}{*}{3} & \multirow[t]{3}{*}{ Laki-laki } & $\begin{array}{l}\text { Habis/ tak } \\
\text { dipakai }\end{array}$ & 18 & 43.90 \\
\hline & & $\begin{array}{l}\text { Berkembang/ } \\
\text { bermanfaat }\end{array}$ & 1 & 2.44 \\
\hline & & diberikan Anak & 2 & 4.88 \\
\hline 4 & $\begin{array}{l}\text { Laki-laki diberikan } \\
\text { pada Laki-laki }\end{array}$ & diberikan Anak & 1 & 2.44 \\
\hline \multirow[t]{2}{*}{5} & \multirow{2}{*}{$\begin{array}{l}\text { Perempuan } \\
\text { diberikan pada } \\
\text { Laki-laki }\end{array}$} & diberikan Anak & 1 & 2.44 \\
\hline & & $\begin{array}{c}\text { Habis/tak } \\
\text { dipakai }\end{array}$ & 1 & 2.44 \\
\hline & & & 41 & 100 \\
\hline
\end{tabular}

Sumber : Data Primer diolah

Pada tabel 4 tersebut nampak jika bantuan yang dimanfaatkan Perempuan, baik yang didapatkan atas nama sendiri maupun yang didapatkan atas nama suami atau orangtuanya, lebih besar kesempatan untuk berkembang/bermanfaatnya $(12,20 \%$ dan 19,51\%) jika dibandingkan dengan yang dimanfaatkan langsung oleh Laki-laki $(2,4 \%)$. Bahkan jika kita perhatian dari sisi kegagalan dalam pemanfaatan bantuan tersebut nampak juga jika bantuan yang dimanfaatkan Laki-laki secara langsung lebih besar kegagalannya (43,90\% dan 2,44\%) dibandingkan dengan yang dimanfaatkan Perempuan secara langsung $(7,32 \%$ dan $2,44 \%)$.

Untuk itu kita dapat merancang suatu model percepatan pengentasan kemiskinan yang berbasis pemberdayaan perempuan, yaitu program bantuan untuk RTSM baik yang kepala rumah tangganya perempuan maupun salah satu anggota keluarganya perempuan, namun 
dengan syarat perempuan tersebut tergolong produktif (baik usia maupun kemampuannya), sehingga program bantuan baru ini dapat lebih efektif dalam mencapai tujuan untuk membantu RTSM tersebut.

Berdasarkan program yang lalu nampak jika untuk kalangan perempuan lebih cocok dengan bantuan berupa warung sembako, namun selalu terkendala besarnya modal, maka bentuk pemberdayaan yang tepat untuk mereka adalah penguatan permodalan yang dapat diberikan dalam bentuk hibah modal bergulir, dimana pengelolaannya dapat memanfaatkan kelembagaan masyarakat yang sudah ada.

\section{KESIMPULAN}

1. Faktor-faktor yang dapat mendukung dan menghambat efektifitas program JALINKESRA di wilayah Kelurahan Bunulrejo, Kecamatan Blimbing, Kota Malang, antara lain :

a. Faktor-faktor Internal Implementasi Program Jalinkesra :

Peluang : Usaha/pekerjaan lain RTSM, keadaan penduduk, potensi perdagangan, potensi industri, kondisi kelembagaan masyarakat, kondisi sarana dan prasarana, Bantuan anak/keluarga dan bantuan lain pemerintah.

Ancaman : Kepemilikan lahan usaha RTSM, persaingan usaha, kondisi fisik RTSM, Ketrampilan RTSM, jumlah anggota keluarga tertanggung, tingkat pendidikan RTSM, potensi SDA dan kearifan lokal/budaya masyarakat.

b. Faktor-faktor Internal Implementasi Program Jalinkesra :

Kekuatan : Proses administrasi penyerahan bantuan, proses pendataan, kondisi bantuan saat penyerahan, proses konfirmasi, jenis bantuan, jumlah bantuan dan proses sosialisasi/penjelasan.

Kelemahan : Jangka waktu, kualitas bantuan, pendampingan/ bimbingan teknis, pengawasan/monitoring dan evaluasi.

2. Alternatif rancangan model percepatan pengentasan kemiskinan RTSM di wilayah Kelurahan Bunulrejo, Kecamatan Blimbing, Kota Malang, antara lain : 
Alternatif 1 : Meminimalisir masalah-masalah (kelemahan-kelamahan) internal program yang sudah ada, melalui terobosan-terobosan untuk perbaikan sistem.

Alternatif 2 : Model percepatan pengentasan kemiskinan yang berbasis pemberdayaan perempuan, yaitu program bantuan untuk RTSM baik yang kepala rumah tangganya perempuan maupun salah satu anggota keluarganya perempuan, namun dengan syarat perempuan tersebut tergolong produktif (baik usia maupun kemampuannya).

\section{SARAN}

1. Dalam pengadaan bantuan perlu adanya quality control, sehingga kualitas bantuan akan terjaga, demi mencapai efektifitas program.

2. Perlu adanya penataan kembali sistem pendampingan/ bimbingan teknis, monitoring dan evaluasi secara kontinyu untuk RTSM penerima manfaat agar bantuan yang diterima dapat dimanfaatkan dengan lebih baik (optimal).

\section{UCAPAN TERIMAKASIH}

Ucapan terima kasih kami haturkan untuk Bapak Dr. H. Soekarwo, SH, H. Hum, Gubernur Jawa Timur dan Ketua Program Magister Ilmu Sosial dan Ilmu Politik Prof.Dr.Ir.Sanggar Kanto, M.Si yang telah membimbing kami.

\section{DAFTAR PUSTAKA}

Anonymous, 2010, Pedoman Umum Program Jalan Lain Menuju Kesejahteraan Rakyat (Jalin Kesra) Bantuan Rumah Tangga Sangat Miskin (RTSM) Provinsi Jawa Timur Tahun 2011, Gubernur Provinsi Jawa Timur, Surabaya.

Arikunto, Suharsimi. 2010. Prosedur Penelitian Suatu Pendekatan Praktik, Edisi Revisi. PT. Rineka Cipta. Yogyakarta.

Creswell, John W, 2009, Research Design Pendekatan Kualitatif, Kuantitatif dan Mixed, Pustaka Pelajar, Yogyakarta

Sugiyono. 2011. Metode Penelitian Kuantitatif, kualitatif dan $R \& D$, Penerbit Alfabeta, Bandung 
Kurniawan, Yudiyanto T, 2015a, Strategi Optimalisasi Implementasi Jaminan Kesehatan Nasional untuk keluarga miskin di Puskesmas Kedamean, Malang

Kurniawan, Yudiyanto T, 2015b, Dampak Program Jalinkesra Dalam Peningkatan Kualitas Hidup Sumberdaya Manusia Pada Rumah Tangga Sangat Miskin (RTSM), Studi kasus di Kelurahan Bunulrejo, Kecamatan Blimbing Kota Malang, Surabaya.

Kurniawan, Yudiyanto T, 2017, Faktor-faktor dan pola hubungannya yang mempengaruhi pemanfaatan Jaminan Kesehatan Nasinal (JKN) oleh keluarga miskin, Studi kasus di Puskesmas wilayah Kecamatan Kedamean Kabupaten Gresik, Surabaya.

Muyasara, Siti, 2010, Analisa SWOT terhadap Produk Asuransi Unit LINK, Studi pada PT.Asuransi Takaful Keluarga, Jakarta.

Moleong, J.L. 2012. Metodologi Penelitian Kualitatif, Edisi Revisi, P.T. Remaja Rosdakarya, Bandung.

Rangkuti, Freddy, 2002, Analisis SWOT Teknik Membedah Kasus Bisnis, Reorientasi Konsep Perencanaan Strategis untuk menghadapi Abad 21, Penerbit PT Gramedia Pustaka Utama, Jakarta.

https://jatim.bps.go.id/linkTabelStatis/view/id/605 diunduh tanggal 22-09-2017 pukul 07.03 WIB. 